\title{
A ORIGEM DA ESTAÇÃO FERROVIÁRIA DE PRESIDENTE PRUDENTE
}

\author{
Luana Rodrigues, Flórian Alonso, Mariana Pompei, Fernando Piffer, Korina Costa \\ Universidade do Oeste Paulista - UNOESTE. Curso de Arquitetura e Urbanismo, Presidente Prudente - SP.
}

\section{RESUMO}

Desde que foi implantada, em 1937, a chamada Lei do Tombamento, muitos edifícios estão sendo poupados, porem no Oeste Paulista atualmente pouco se tem conhecimento sobre a necessidade de preservar um patrimônio. As origens da primeira Estação Ferroviária de Presidente Prudente construída em 1919, remontam desde a primeira iniciativa conhecida da vinda dos trilhos da Sorocabana pelos produtores de café, desbravando a região. Possui um estilo pioneiro, conforme se fazia na época, por isso a importância de analisar como se deu sua história até o momento de sua demolição, dando lugar à um novo edifício sem atentar-se em mantê-la para as gerações futuras. O presente trabalho faz parte de um projeto maior, que engloba outras estações ferroviárias e visa promover um estudo dseu valor histórico e cultural, para que haja um direcionamento para e seu tombamento, por estar o mesmo ainda em fase de início, será apresentada a sua primeira etapa, que é a pesquisa de sua implantação.

Palavras chave: Estação Ferroviária, Patrimônio, Sorocabana, Memoria Cultural, Presidente Prudente

\section{THE ORIGIN OF RAILWAY STATION PRESIDENTE PRUDENTE}

\begin{abstract}
Since it was implemented in 1937, called the Law of Tipping, many buildings are being spared, however the West Paulista currently little is known about the need to preserve a heritage. The origins of the first railway station of Presidente Prudente built in 1919, dating from the first known initiative of the coming of the rails Sorocabana by coffee producers, braving the region. It has a pioneer style, as was done at the time, so the importance of analyzing how was your story until the moment of its demolition, giving way to a new building with little regard on maintaining it for future generations. This work is part of a larger project that includes other railway stations and aims to promote a study of its historical and cultural value, so there is a direction for her and tipping it to be still in the beginning stage, will be presented to its first stage, which is the research of its implementation.
\end{abstract}

Keywords: Train Station, Heritage, Sorocabana, Cultural Memory, Presidente Prudente 


\section{INTRODUÇÃO}

Este estudo, diz respeito à criação da estação de trem de Presidente Prudente, fazendo parte do Projeto de Pesquisa sobre as Estações de Trem da Estrada de Ferro Sorocabana, pois muito se fala sobre a colonização da cidade, porém, pouco se aprofunda nas suas origens, anterior à chegada dos coronéis, entre o final do séc. XIX e começo do séc. $X X$, estimulando a vinda de muitas pessoas, bens e serviços, assim como a venda e aquisição de terras em toda a região.

Neste sentido, conforme consta no Arquivo, Instituto Histórico, Geográfico e Genealógico de Sorocaba, a construção da estação do Município de Presidente Prudente surge para dar suporte à ferrovia neste trecho, contendo serviços de manutenção da mesma e ao serviço de carga e descarga de mercadorias, passageiros e animais. Desta forma, em 1919, com o incentivo do Governo Federal, um edifício sede foi construído na Praça da Bandeira, na Rua Júlio Tiezzi - ao fim da Avenida Washington Luiz e início do Viaduto Comendador Tannel Abud.

Segundo Alvaro Viotti Vieira (2011), o transporte ferroviário de passageiros e mercadorias é mais econômico e seguro que o rodoviário e, para os deslocamentos de grandes distâncias, os brasileiros deveriam seguir o exemplo das nações mais desenvolvidas, fazendo uso dele em grande escala. Porém o que vem ocorrendo é o oposto, pois muitas ferrovias vêm sendo fechadas e estão tendo seus trilhos retirados, o que para ele é um crime contra patrimônio nacional.

Conforme O Tombamento DECRETO-LEI N²5 de Novembro de 1937, em seu capítulo 1, artigo 10:

Constitui o patrimônio histórico e artístico nacional o conjunto dos bens móveis e imóveis existentes no país e cuja conservação seja de interesse público, quer por sua vinculação a fatos memoráveis da história do Brasil, quer por seu excepcional valor arqueológico ou etnográfico, bibliográfico ou artístico.

Visando fomentar as discussões e direcionar caminhos para as ações, surge a Carta de Veneza definida no II $^{\circ}$ Congresso Internacional de Arquitetos e Técnicos de Monumento Histórico, em 1964 com o princípio de transmitir as gerações futuras a riqueza da sua autenticidade atreves de alguns pontos que nos permite classificar como: Cultural, Artístico, Histórico, Sociais e Científicos os patrimônios da humanidade.

A E.F.S. de Presidente Prudente teve seu primeiro edifício sede construído em meados de 1920, foi demolido e passou a dar lugar a uma nova estação, construída conforme os princípios do estilo Art Decô, sofrendo algumas pequenas reformas para conservação e manutenção, porém sem agredir suas características originais. 
Não há registros exatos de quando, mas o edifício chegou a ser tombado como Patrimônio Histórico Cultural, registrado com o número: NP710685, posteriormente, deixa de possuir tal título e em 2009 passa a sediar a Fundação PROCON (Fundação de Proteção e Defesa do Consumidor) administrada pela Prefeitura Municipal de Presidente Prudente, quando é submetido a mais uma reforma, que interfere nas suas subdivisões internas, através de paredes divisórias de fórmica e gesso, para atender programa de necessidades da fundação ali implantada, assim como para atender às leis de acessibilidade NBR-9050.

Assim, objetiva-se pesquisar a relevância da linha férrea e da estação ferroviária para a formação do município e o valor que foi construído historicamente para a memória cultural da cidade de Presidente Prudente. Estando o presente estudo em sua fase inicial, a pesquisa focará em apresentar os estudos sobre a primeira edificação construída, verificando sua importância para a época e buscando parâmetros para compreender os condicionantes de sua demolição e substituição por outra edificação. Para tanto, pesquisar as teorias e conceitos sobre a preservação do patrimônio histórico cultural, visando compreender quais são os direcionamentos sobre tal temática.

\section{METODOLOGIA}

A pesquisa foi desenvolvida com base nos livros que tratam de assuntos da época em estudo e suas características arquitetônicas, assim como nas obras ligadas ao Patrimônio Histórico Cultural, vistas ao museu e ao local de estudo. Além de pesquisas na internet, foi somado o conhecimento adquirido no ambiente acadêmico, cuja investigação se fundamentará na abordagem qualitativa de pesquisa, utilizando-se da pesquisa de levantamento bibliográfico e da pesquisa documental, que segundo Teixeira (2000, p. 137), busca a correlação entre a teoria e os dados, entre o contexto e a ação, a partir da compreensão dos fenômenos por meio de sua descrição e interpretação. Para o trabalho com o estudo do tipo de levantamento bibliográfico ocorrerá inicialmente um levantamento das principais produções no contexto nacional de estudos, considerando a peculiaridade do objeto de estudo.

Desse modo, percebe-se que a pesquisa qualitativa vale-se do método indutivo, segundo o qual parte da observação, da análise dos fatos particulares, dos registros para compor um quadro compreensivo para então constituir a generalização universal, ou seja, a teoria. O processo de indução vale-se do princípio do empirismo, no qual o conhecer é dar significado à realidade (KÖCHE, 1997, p. 62). 
A ESTRADA DE FERRO SOROCABANA

A cidade de Presidente Prudente está situada no extremo oeste do Estado de São Paulo. Fundada em 1917, sendo elevada à título de município em 1921. De acordo com dados do IBGE de 2010, possuía 207.610 habitantes.

A expansão da lavoura cafeeira impulsionou a construção da malha ferroviária pelo Barão de Nova Friburgo, Antônio Clemente Pinto (MACEDO, 2006), seguindo pela Serra Fluminense e espalhando-se por São Paulo, Minas Gerais e Espirito Santo (SILVA, COSTA, 2013). Porém, com a abolição da escravatura, a base da economia cafeeira sofreu uma queda, quando o plantio do café se expande para o extremo oeste do Estado em busca de terras férteis, uma região ainda pouco conhecida no século XIX.

A primeira iniciativa de se construir uma linha férrea em tal região, partiu de uma lei, escrita pelo Regente Pe. Diogo Antônio Feijó, em 1835.

Primeira Lei Geral: Lei no 101, de 31 de Outubro de 1835, do Regente Pe. Diogo Antônio Feijó , constituindo-se na primeira tentativa de estabelecer um caminho de ferro no país. Por falta de recursos financeiros e em função da pequena população dos núcleos que justificasse a construção a tentativa não teve êxito. (MACEDO, 2006)

A segunda lei geral, de 1852, autoriza a construção, interligando o Rio de Janeiro, São Paulo e Minas Gerais. Pouco anos mais tarde, em 1855, foi firmado um contrato para a construção da estrada de ferro no Rio de Janeiro.

Lei de 10 de maio de 1855 - firmado contrato para a construção de uma estrada de ferro por conta do Tesouro Nacional e recursos da província do Rio de Janeiro, num prazo de 33 anos, sob responsabilidade de E. Price, com 37,5 milhas. A nova empresa foi denominada Companhia de Estrada de Ferro D. Pedro II: partiria do Rio de Janeiro e se dividiria em dois ramais entre a Serra do Mar e Rio Paraíba, atingindo o povoado de Cachoeira em São Paulo, onde chegou em julho de 1875. (MACEDO, 2006)

Segundo Ronaldo Macedo (2012), as principais linhas foram da Estação Ferroviária Santos Jundiahy, atualmente Paulista, a Companhia Ituana, construída em 30 de junho de 1870, a Mogiana, criada em 1872, que foi a mais importante do pais, pois ligava Campinas a Mogi Mirim com uma linha tronco na cidade de Ribeirão Preto, na época muito promissora na produção cafeeira; e a Sorocabana, objeto de estudo deste trabalho.

A Estação Ferroviária Sorocabana foi fundamental na criação dos municípios localizados na região do Pontal do Paranapanema, porém, de acordo com Abreu (1972) apud Silva e Costa 
(2006), a motivação de sua construção, ocorreu devido aos incentivos de Luiz Matheus Maylasky e não seria para escoamento da produção de café, mas sim para o transporte ligado à exportação de ferro produzido pela fábrica São João do Ipanema, abastecendo todo o país.

O primeiro trecho da ferrovia foi e entregue ao tráfego em julho de 1875 , fazendo a ligação da cidade de São Paulo à Sorocaba e passou a expandir-se para as demais cidades da região - em direção ao Rio Paraná - para atender o transporte da produção agropecuária da época. (MACEDO, 2006)

Os avanços dos trilhos trouxeram para a região pessoas de diversas regiões do país, que tiveram extrema importância no povoamento que foi surgindo nos arredores da estação. Num segundo momento vieram para a cidade as companhias de colonização, originando o núcleo urbano de Presidente Prudente através da iniciativa dos Coronéis José Soares Marcondes e Francisco de Paula Goulart. Após a Primeira Guerra Mundial, a região do Paranapanema passava a expandir sua produção cafeeira, sendo a E.F.S., uma importante peça para fomentar o surgimento de vários núcleos urbanos na região, como no caso do município de Presidente Prudente.

\section{A PRIMEIRA ESTAÇÃO FERROVIÁRIA DE PRESIDENTE PRUDENTE}

Segundo Ronaldo Macedo (2006) a primeira iniciativa de se construir uma Estação Ferroviária foi o envio de uma planta baixa de São Paulo pelo Engo Sebastião Ferraz, responsável pelo trecho.

De acordo com o site Estações Ferroviárias, que pode ser acessado pelo domínio <http://www.estacoesferroviarias.com.br/p/presprudente.html>, o posto telegráfico de Presidente Prudente, instalado em um vagão de trem, funcionava como ponto de embarque e desembarque e, posteriormente seria o núcleo da futura cidade, que foi gerada em torno desse vagão.

Consta nos registros históricos do município, foi construído um edifício em 1919, de estilo rudimentar, uma arquitetura pioneira, pois contava com a participação da população pra sua execução. Foi fundamental a sua relação com os centros urbanos iniciais de Presidente Prudente, pois formou-se uma barreira que proporcionou o seu crescimento para ambos os lados da linha férrea e tornou-se o ponto com maior fluxo e circulação da época.

O surgimento da Vila Goulart surgiu através de Francisco de Paula Goulart, que defronte a linha férrea, separou a sua propriedade em uma fazenda e uma rua, atual Washington Luiz, que serviu como base para a determinação e arruamento do primeiro núcleo de povoamento da Presidente Prudente. Foram facilitadas as compras para que os interessados se fixassem 
rapidamente (MACEDO, 2006). Com a chegada do Cel. José Soares Marcondes em 1919, foi iniciado o loteamento de sua propriedade do outro lado da linha férrea, oposta a Vila Goulart atual centro administrativo.

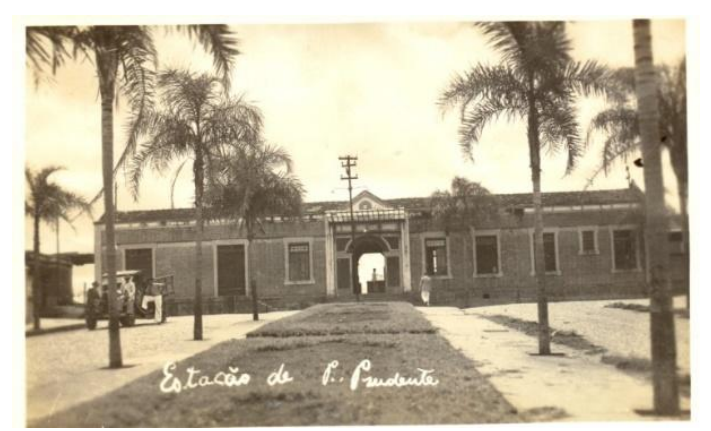

FIGURA 01. Esplanada da estação ferroviária em 1938

Fonte - Acervo Museu Municipal

Os trens da Sorocabana permitiram a chegada dos novos moradores dos loteamentos, ou apenas interessados no trabalho ou no comércio cafeeiro. Conforme as vilas foram tornando-se maiores e mais povoadas, houve a necessidade de obras de infraestrutura para melhorar as condições básicas nos latifúndios e atrair interessados para ocupação e crescimento dos novos núcleos urbanos.

Alguns anos mais tarde, o primeiro edifício-sede foi demolido para dar lugar a uma nova estação, mais moderna em relação ao edifício já existente e que oferecesse assistência à crescente demanda de transporte de cargas e pessoas na cidade e região, sendo erigida com novas características arquitetônicas, conhecida como estilo Art Decô.

O novo aspecto apresenta aquela parte da cidade que se sentia prejudicada em sua estética pelo velho edifício; hoje a impressão é outra, dado o acabamento de linhas futuristas e sóbria que encerra o movimentado centro exportação e importação de Presidente Prudente. (Jornal O Imparcial, 16 de Abril de 1944.)

O novo prédio foi construído dentro dos mesmos limites do prédio anterior, porém com especificidades decorrentes do novo programa de necessidades, como a construção em dois pavimentos, uma escadaria imponente no saguão e fachada envidraçada contribuindo para o aspecto moderno da edificação no contexto de sua execução.

\section{A IMPORTÂNCIA DO TOMBAMENTO ARQUITETÔNICO}

O instituto do tombamento foi firmado pela primeira vez em 30 de novembro de 1937, com a publicação do Decreto-Lei no 25, usualmente chamado de Lei do Tombamento. 
Para Celso Antônio Bandeira de Mello (2009) apud Holanda (2010), o tombamento é visto como uma intervenção administrativa na destinada a resguardar o patrimônio histórico e artístico nacional, além de restringir alguns usos, pois o proprietário faz uso do local, mas não deve alterálo, além de ficar estabelecido no dever de mantê-lo em boa conservação.

Assim como muitas cidades brasileiras com o mesmo histórico de fundação decorrente da passagem da linha férrea, a cidade de Presidente Prudente não possui um vínculo com a memória ou a identidade dos edifícios mais antigos (HIRAO, 2012). Isso ocorre por parte da população e dos atores políticos, que justificam ser a cidade muito recente para "acumular as produções das várias gerações anteriores", procurando sustentar-se em nome do progresso da cidade, que não há espaço para edifícios históricos.

De acordo com Jane Jacobs (1961), toda cidade necessita ter diversidade de edifícios antigos e estados de conservação variados, por considerar que a vitalidade do lugar se encontra nessas confluências de datas, gerando uma espécie de contagem da história da cidade através das construções.

Ainda segundo Hélio Hirao (2012), conjuntos com grandes valores estéticos e artísticos em Presidente Prudente, incluindo o Art Deco, Protomodernismo e Modernismo são dependentes do interesse público local para serem preservados.

\section{CONCLUSÃO}

Numa visão geral do Pontal do Paranapanema, pode-se constatar que a linha férrea promoveu a criação da maioria das cidades desta região, como salienta Villaça (2001), onde era usada para escoamento de produtos, "as ferrovias provocam crescimento descontinuo e fortemente nucleado, em que o núcleo ou o polo se desenvolve junto às estações".

Como parte integrante deste contexto de configuração urbana, está também a cidade de Presidente Prudente, sua linha férrea e estação ferroviária, que chegaram à localidade antes mesmo que essa se tornasse município, sendo assim um marco representativo para a história local, estando presente em todos os momentos que se seguiram. Porém, tal primeira estação foi demolida devido a falta de leis cabíveis de tombamento do patrimônio e com ela se perdeu parte da memória cultural de Presidente Prudente.

Cabe ao tombamento garantir ao edifício a preservação de suas características originais, propiciando a continuidade de sua representatividade a gerações futuras. Não havendo edificação, não há também o que se preservar, tal pressuposto direciona para a importância de se manter a história viva enquanto a mesma encontra-se representada, neste caso através de sua arquitetura. 
Assim, espera-se com a sequência do estudo, promover a documentação necessária para se iniciar o processo de tombamento da atual edificação e com ela a preservação de boa parte da memória coletiva.

\section{REFERÊNCIAS}

ABREU, Dióres Santos. Formação histórica de uma cidade pioneira Paulista: Presidente Prudente. Presidente Prudente: FFCLPP, 1972.

ESTAÇÕES FERROVIÁRIAS, http://www.estacoesferroviarias.com.br/p/presprudente.html.

HIRAO, Helio. FLOETER, Roberto A. O Patrimônio Arquitetônico e Urbanístico de Presidente Prudente: O Possível Preservado. Presidente Prudente - 2012.

HOLANDA, Marcella Carneiro. O tombamento como instrumento de preservação do patrimônio histórico e cultural. Trabalho publicado nos Anais do XIX Encontro Nacional do CONPEDI realizado em Fortaleza - CE nos dias 09, 10, 11 e 12 de Junho de 2010.

JACOBS, Jane. Morte e Vida de Grandes Cidades.1961. 3a ed. São Paulo, Martins Fontes, 2000.

KÖCHE, J. C. Fundamentos de metodologia científica: teoria da ciência e iniciação à pesquisa. 22 . ed. São Paulo: Vozes, 2004.

LEITE, José Ferrari. A Alta Sorocabana e o espaço polarizado de Presidente Prudente. Faculdade de Filosofia, Ciências e Letras de Presidente Prudente. São Paulo, 1972, pg. 119.

MACEDO, Ronaldo. A História de Presidente Prudente. 2006.

MELLO, Celso Antônio Bandeira de. Curso de Direito Administrativo. 26 ed. São Paulo: Malheiros, 2009.

SILVA, Matheus Dias da. COSTA, Prof. Dr. Luiz Augusto Maia. A criação da cidade de Presidente Prudente e seu desenvolvimento até a atualidade. 1917 - 1970, 2013, CEATEC - PUC Campinas.

TEIXEIRA, E. As três metodologias. 2ạ.ed. São Paulo: Vozes, 2000.

VIEIRA, Alvaro Viotti. Instituto Histórico, Geográfico e Genealógico de Sorocaba. Publicado em 2014. Disponível em: http://www.ihggs.org.br/index2.php?option=content\&do pdf=1\&id=151.

VILLAÇA, Flavio, 1929. Espaço intra-urbano no Brasil. São Paulo: Studio Nobel: FAPESP. Lincoln Institute, 2001. HIRAO. 